\title{
FTIR microscopy as a method for detection of retrovirally transformed cells
}

\author{
Mahmoud Huleihel*, Marina Talyshinsky and Vitaly Erukhimovitch \\ The Institute for Applied Biosciences, Ben-Gurion University of the Negev, POB 653, Beer-Sheva \\ 84105, Israel
}

\begin{abstract}
Fourier transform infrared (FTIR) spectroscopy is a unique technique that has potential for the optical diagnosis of cellular variations based on the characteristic molecular vibrational spectra of the cells. In the present study, a refinement of this technique - FTIR microscopy - was used in a mouse model to investigate spectral differences between primary cells and malignant cells transformed by murine sarcoma virus (MuSV). The advantage of FTIR microscopy is that it facilitates inspection of a restricted region of cell growth on a slide. A significant decrease in the intensities of the spectra was seen in malignant cells transformed by MuSV compared to primary normal cells. Also, there was a significant shift in the $\mathrm{PO}_{2}^{-}$ symmetric stretching mode from $1082 \mathrm{~cm}^{-1}$ for normal cells to $1086 \mathrm{~cm}^{-1}$ for malignant cells. Detectable and consistent differences between normal primary and malignant cells were evident in the shapes and positions of a number of peaks in the FTIR spectra. Our results indicated that FTIR microscopy has potential as a diagnostic method for the detection of malignant cells.
\end{abstract}

\section{Introduction}

The invasive and metastatic potential of cancer cells is a result of their lack of ability to control proliferation and differentiation in an integrated manner. It is currently accepted that viruses play a major role in the etiology of cancer: both DNA and RNA viruses have the ability to induce carcinogenesis [7]. Among the retroviruses that have been implicated in various types of human and animal leukemias and other tumors are Rous sarcoma virus, Avian sarcoma virus, and Moloney murine sarcoma virus (MuSV) $[6,8,11,18]$. Retroviruses carry oncogenes $[1,10]$ that have the potential to transform normal cells into cancerous cells. These oncogenes are derived from the host cellular genes, which are usually mutated and expressed constitutively in the transduced cells.

A standardized laboratory technique for early detection of various types of cancers would greatly contribute to reducing the huge number of cancer-related deaths that occur throughout the world each year. Such a technique would be especially useful in developing countries, for which mortality rates from cancer are slightly higher than those in developed countries: Of the estimated annual 5.2 million deaths from cancer throughout the world, 55\% (2.8 million) occur in developing countries [14]. Scientists have recently begun exploring the application of Fourier transform infrared (FTIR) spectroscopy in biomedicine $[4,12]$. In particular, the technique may be used to detect and monitor characteristic changes in molecular compositions and structures that accompany a transformation from a normal to a cancerous state $[3,5,13,15,20]$. Several features of infrared absorption spectroscopy demonstrated that FTIR could be applied as an accurate and sensitive method for in vivo diagnosis of malignant diseases: (1) in general, IR has a lower absorption coefficient of vibration motion and suffers less tissue scattering compared to

\footnotetext{
*Corresponding author. Tel.: +972 8 6461999; Fax: +972 8 6472970; E-mail: mahmoudh@bgumail.bgu.ac.il.
} 
UV and visible radiation; and (2) there are many resolved vibration bands in the IR region, and subtle changes in the molecular structure may therefore be monitored during development of the disease.

One of the problems associated with spectral measurements of cells from in vivo tumors is that such tumors often contain normal cells, necrotic material, fibrous components, blood, tissue fluid and other materials in addition to malignant cells. We applied a two-pronged approach to circumventing this complication: (1) we used FTIR microscopy, which enabled us to focus solely on the relevant regions of a tissue section; and (2) we used primary cells rather than the cell lines used in previous studies [23], since primary cells are similar to normal tissue cells in most of their characteristics, while cell lines have some characteristics in common with malignant cells, such as the high rate of replication. This study thus constitutes one of the first steps towards the development of novel diagnostic methods based on FTIR that will provide an objective measure of malignancy, which is not always available in currently used pathological methods.

\section{Materials and methods}

\subsection{Cells and viruses}

Mouse primary fibroblast cells and mouse primary kidney cells were obtained from the bone marrow and kidneys, respectively, of newborn mice. The kidneys were cut into small pieces and treated with a trypsin for several minutes at $37^{\circ} \mathrm{C}$. Both fibroblast and kidney primary cells were grown at $37^{\circ} \mathrm{C}$ in RPMI medium supplemented with $10 \%$ newborn calf serum (NBCS) and the antibiotics penicillin, streptomycin and neomycin. Clone 124 of TB cells chronically releasing Moloney MuSV-124 [2] was used to prepare the appropriate virus stock.

\subsection{Cell proliferation}

Cells, seeded at a concentration of $0.6 \times 10^{6}$ cells per $9.6 \mathrm{~cm}^{2}$ plate, were incubated at $37^{\circ} \mathrm{C}$ in RPMI supplemented with $10 \%$ NBCS and antibotics. Each day, the cells were examined for morphological changes, and the number of cells was counted with a hemacytometer.

\subsection{Cell infection and determination of cell transformation}

A monolayer of fibroblast or kidney cells grown in $9-\mathrm{cm}^{2}$ tissue culture plates was treated with $8 \mu \mathrm{g} / \mathrm{ml}$ of polybrene (a cationic polymer required for neutralizing the negative charge of the cell membrane) for $24 \mathrm{~h}$ before infection with the virus. Excess polybrene was then removed, and the cells were incubated at $37^{\circ} \mathrm{C}$ for $2 \mathrm{~h}$ with the infecting virus (MuSV-124) at various concentrations in RPMI medium containing $2 \%$ of NBCS. The unabsorbed virus particles were removed, fresh medium containing $2 \%$ NBCS was added, and the monolayers were incubated at $37^{\circ} \mathrm{C}$. After $2-3$ days, the cell cultures were examined for the appearance of malignant transformed cells.

\subsection{Soft agar assay}

A mixture of $25 \%$ of $2 \%$ Bacto agar, $25 \%$ of RPMI $\times 2,20 \%$ of NBCS and $30 \%$ of RPMI was prepared, and $4 \mathrm{ml}$ of this mixture was poured into a number of 50-mm petri dishes. The mixture was left to polymerize at room temperature for about $30 \mathrm{~min}$. This procedure gave a solid agar $(0.5 \%)$ layer. 
Onto each solid layer was poured $1 \mathrm{ml}$ of $0.36 \%$ agar containing the test cells. This upper layer was prepared by mixing of $18 \%$ of $2 \%$ Bacto agar, $18 \%$ of RPMI $\times 2,20 \%$ of NBCS and $44 \%$ of RPMI. About $10^{5}$ cells were added to each plate. The plates were left at room temperature for about $20 \mathrm{~min}$ and then incubated at $37^{\circ} \mathrm{C}$ in humidified air containing $5 \% \mathrm{CO}_{2}$ for about 14 days. At the end of the incubation period, colonies of transformed cells were counted under a light microscope.

\subsection{Preparation of slides}

Since the ordinary glass slides exhibit strong absorption in the wavelength range of interest to us, we used zinc sellenide crystals, which are highly transparent to IR radiation. Cells were grown on such crystals to the required high densities, then washed twice with phosphate-buffered saline (PBS), dried, and examined by FTIR microscopy.

\subsection{FTIR measurements}

FTIR measurements were performed in transmission mode with a liquid-nitrogen-cooled MCT detector of FTIR microscope (Bruker IR Scope II) coupled to the FTIR spectrometer (BRUKER EQUINOX model $55 / \mathrm{S}$, OPUS software). The spectra were obtained in the wave number range of $600-4000 \mathrm{~cm}^{-1}$ in the mid-IR region. A spectrum was taken as an average of 128 scans to increase the signal to noise ratio and the spectral resolution was at $4 \mathrm{~cm}^{-1}$. Baseline correction (rubber band method) and vector normalization for all the spectra were performed by OPUS Software. This normalization elimenates all variations in tested samples thickness.

\section{Results and discussion}

\subsection{Cell proliferation}

The primary fibroblast and kidney cells replicated very slowly in culture (Fig. 1) and could not survive high densities: most of them are died after about 10 passages. In contrast, the malignant cells grew

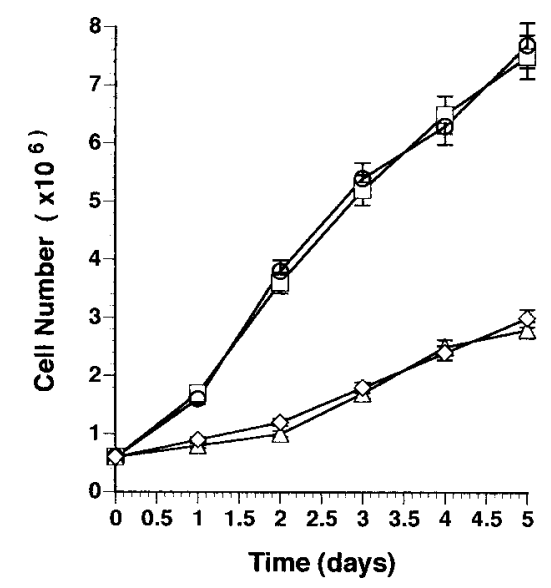

Fig. 1. Cell proliferation. Cells were incubated at $37^{\circ} \mathrm{C}$ and counted at various times after plating. $(\diamond)$ Normal primary mouse fibroblast cells (MF); $(\triangle)$ normal primary mouse kidney cells (MK); (०) Transformed MF cells (MFT); ( $\square$ ) Transformed MK cells (MKT). 
rapidly (Fig. 1), reached very high densities in cell culture, and produced large foci. The malignant cells also grew well in soft agar, in which they produced large colonies within 5-10 days. In contrast, the normal cells were not able to grow and produce colonies in soft agar (data not shown).

Such differences between normal and malignant cells could be related to the infra red spectra of these cells.

\subsection{Comparison of IR spectra of normal and retrovirus-transformed cells}

The FTIR spectra of the malignant cells transformed by the MuSV retrovirus differed markedly from those of the normal primary cells taken from bone marrow and kidneys of newborn mice (Fig. 2). The difference between the spectra was evident in the higher intensities of the spectra for normal cells compared to the malignant cells. For both normal and malignant cells, the dominant bands at $1655 \mathrm{~cm}^{-1}$ and $1546 \mathrm{~cm}^{-1}$ were attributed to amide I and II bands of proteins, suggesting that the polypeptide chains of the cells have an $\alpha$-helix structure [21]. The band at $1465 \mathrm{~cm}^{-1}$ was assigned to the $\mathrm{CH}_{2}$ bending mode of lipids in the cell. The bands at $1454 \mathrm{~cm}^{-1}$ and $1397 \mathrm{~cm}^{-1}$ were attributed to asymmetric and symmetric $\mathrm{CH}_{3}$ bending modes of end ethyl groups and branched methyl groups of proteins and lipids, respectively [20]. From information in previous studies [21], we could assign the remaining IR bands as
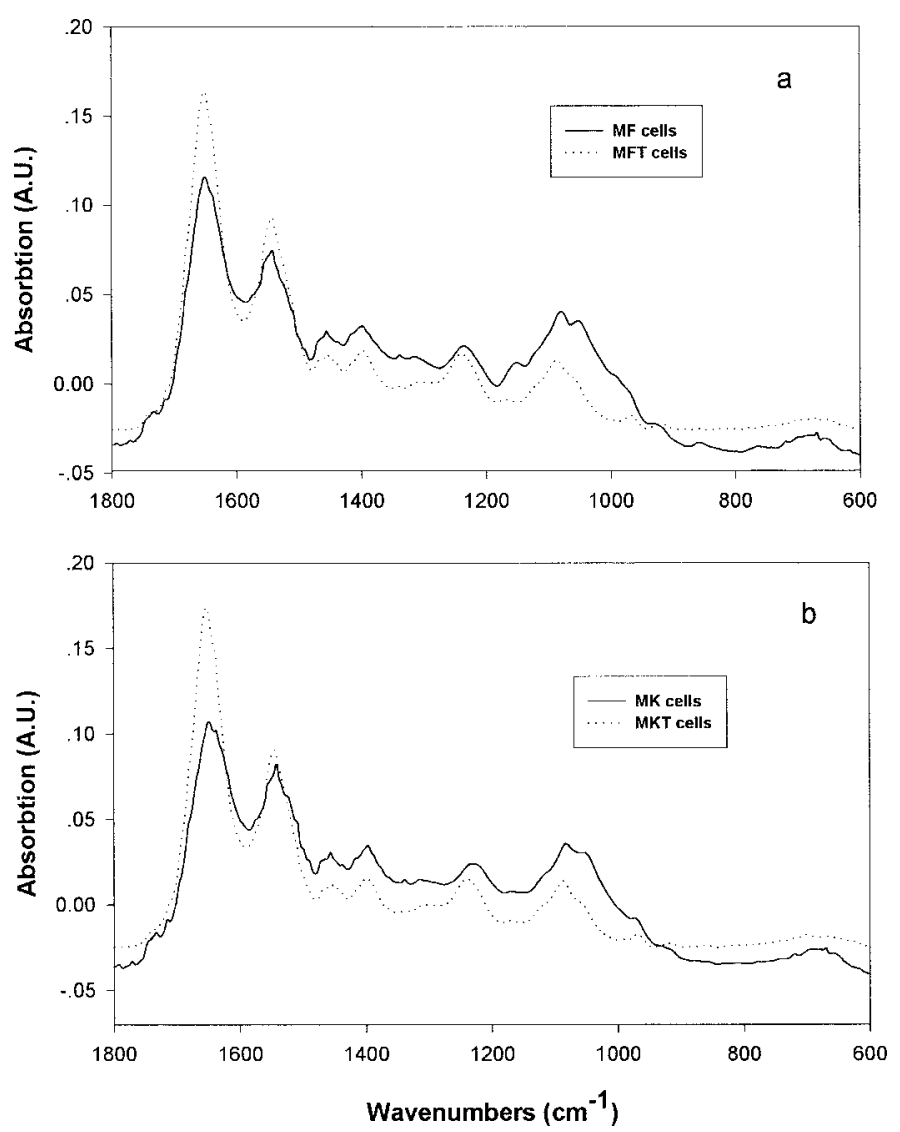

Fig. 2. FTIR microspectroscopy of normal primary (solid line) and malignant (dashed line) cells transformed by murine sarcoma virus (MuSV). (a) Mouse fibroblast cells, (b) mouse kidney cells. Each spectrum is an average of 30 repeats obtained from 10 different animals. The calculated standard deviation (SD) in all tested cases was about \pm 0.01 . 
follows: The peaks at $1237 \mathrm{~cm}^{-1}$ and $1082 \mathrm{~cm}^{-1}$ are due to $\mathrm{PO}_{2}^{-}$asymmetric and symmetric stretching vibrations, respectively, in nucleic acids, for which the contribution of phosphate in the membrane lipids is negligible. The peak at $1064 \mathrm{~cm}^{-1}$ is the result of an overlap of several bands, including absorption due to the vibrational modes of $-\mathrm{CH}_{2} \mathrm{OH}$ and the $\mathrm{C}-\mathrm{O}$ stretching vibration coupled to the $\mathrm{C}-\mathrm{O}$ bending mode of cell carbohydrates. Finally, the band with a maximum at $969 \mathrm{~cm}^{-1}$ may be assigned to the symmetric stretching of $\mathrm{PO}_{4}^{2-}$ in proteins and nucleic acids of the cells [23].

\subsection{Spectra in the $900-1000 \mathrm{~cm}^{-1}$ region}

As shown in Fig. 3 there is a distinct difference in the shape of the peak at $970 \mathrm{~cm}^{-1}$ between normal and malignant transformed cells, the peak being much more focused in the transformed cells vs. the normal primary cells.

\subsection{Spectra in the $1050-1100 \mathrm{~cm}^{-1}$ region}

There was a significant and detectable shift of the peak at $1082 \mathrm{~cm}^{-1}$ for the normal primary cells to $1086 \mathrm{~cm}^{-1}$ in all the tested malignant cells (Fig. 4). A shift in the frequency of this band has been observed in human cells and tissues studied up to date [16,19,21], although that shift in those studies was much smaller than the shift seen in our cells. This difference is probably due to differences in the types of cells used - comparison between cancer cells and primary cells in our study vs that between cancer cells and cell lines $[16,19,21]$. This difference could be also related to differences in the origin of the cells, human or mouse cells. The shift in the peak $1082 \mathrm{~cm}^{-1}$ may indicate that the environment near the $\mathrm{PO}_{2}^{-}$group has undergone a series of alterations during malignancy, which could be related to tumor development and/or to the high rate of replication of these cells, i.e., the high rate of DNA synthesis in the malignant cells. Among the environmental changes detected in cancer cells, hydration in the vicinity of nucleic acids may be a key factor in carcinogenesis [17]. The frequency shift in this band thus probably results from a change in the interaction between nucleic acids and adjacent water molecules.

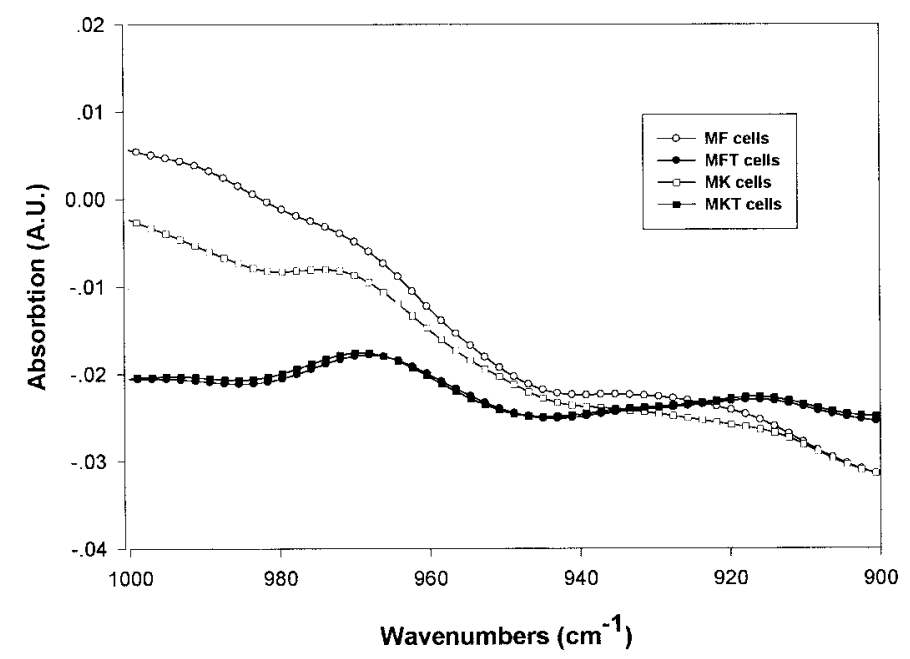

Fig. 3. FTIR microspectroscopy in the region $900-1000 \mathrm{~cm}^{-1}$ of MF, MK, MFT and MKT cells. 


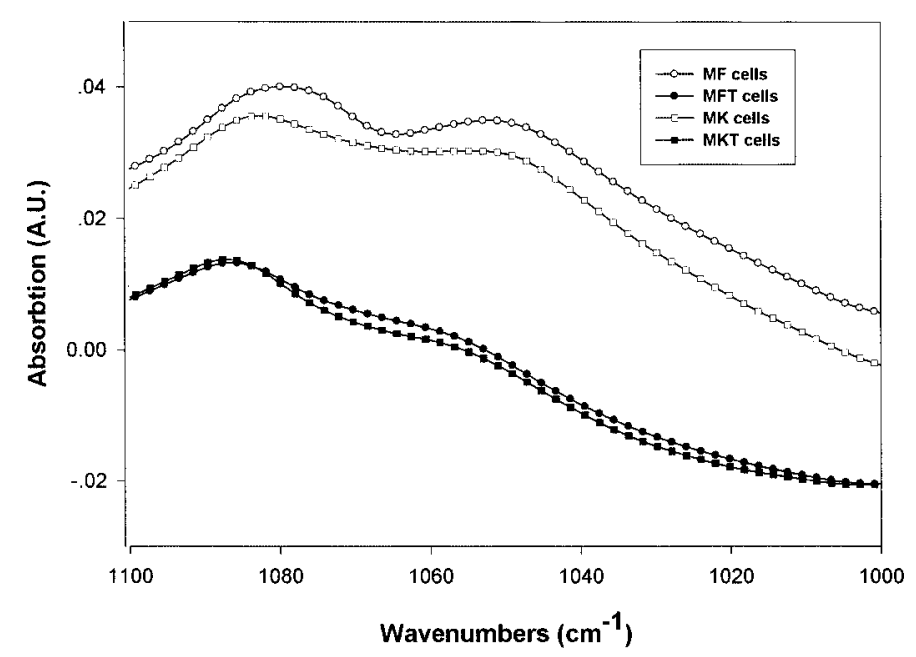

Fig. 4. FTIR microspectroscopy in the region $1000-1100 \mathrm{~cm}^{-1}$ of MF, MK, MFT and MKT cells.

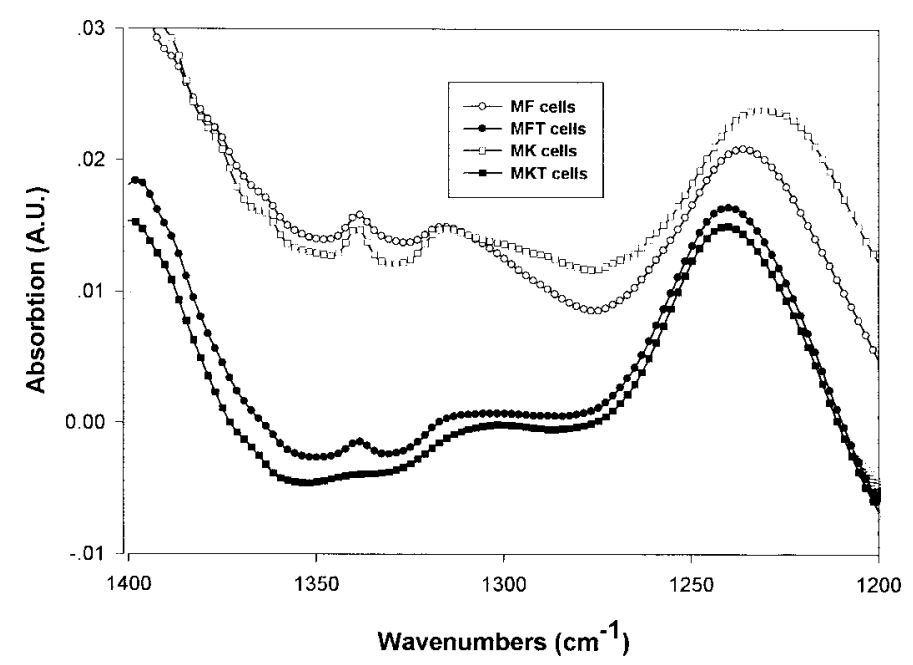

Fig. 5. FTIR microspectroscopy in the region $1200-1400 \mathrm{~cm}^{-1}$ of MF, MK, MFT and MKT cells.

\subsection{Spectra in the $1200-1400 \mathrm{~cm}^{-1}$ region}

The $\mathrm{PO}_{2}^{-}$symmetric and asymmetric stretching vibrations between 1200 and $1400 \mathrm{~cm}^{-1}$ provide clues to qualitative and quantitative changes in phospholipids and nucleic acids. Metabolic turnover is reflected in phosphate levels, which are made up from contributions from energy carriers and producers, such as ATP and GTP, and other biomolecular components, including phospholipids, nucleic acids (DNA and RNA) and phosphorylated proteins. In our study, the intensity of these $\mathrm{PO}_{2}^{-}$vibrations for normal cells was much higher than that for malignant cells in all the tested cases (Fig. 5). These results are in agreement with previously documented FTIR comparisons of cancer and normal tissues and cells $[13,16,21,23]$. In contrast, an IR study on human cervical tissue revealed that the spectrum in the 1200$1400 \mathrm{~cm}^{-1}$ region of normal cervical connective tissue is very similar to that of malignant tissue and that of tumor cells [22]. Similarly, other studies showed that in breast cancer [19] and skin cancer [9] 


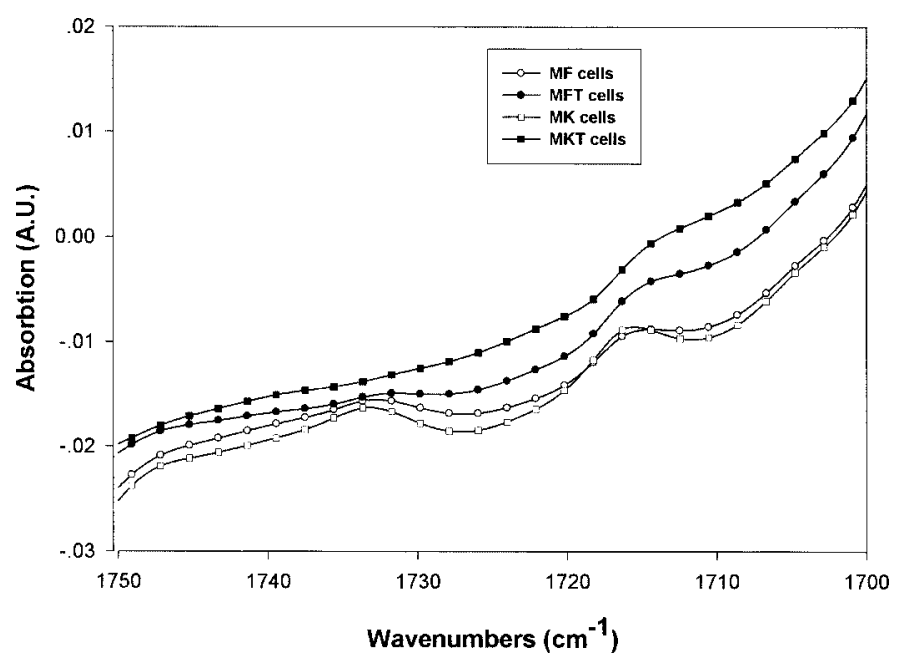

Fig. 6. FTIR microspectroscopy in the region $1700-1750 \mathrm{~cm}^{-1}$ of MF, MK, MFT and MKT cells.

the intensity of $\mathrm{PO}_{2}^{-}$vibrations was higher than that in normal tissues. Such discrepancies could result from the fact that tumors do not consist wholly of malignant cells, but often contain normal cells and a variety of other nonmalignant materials. The differences between our study and previous investigations may be explained by the fact that we used FTIR microscopy, which enabled us to focus on a small predetermined area, whereas the other studies relied on conventional FTIR spectroscopy, which does not facilitate selection of a small specific area.

\subsection{Spectra in the $1700-1750 \mathrm{~cm}^{-1}$ region}

The band at $1730 \mathrm{~cm}^{-1}$ represents the $\mathrm{C}=\mathrm{O}$ stretching of lipids. There were significant differences between normal and malignant cells in the shapes of the bands at 1735 and $1715 \mathrm{~cm}^{-1}$ (Fig. 6). In the primary normal cells these bands were more focused, while in the malignant cells they were flatter.

\section{Conclusions}

This study indicates FTIR microscopy has excellent potential as a diagnostic technique for distinguishing normal from retrovirus-transformed cells. The difference between the spectra for normal and malignant cells was evident in the higher intensities of the spectra for normal cells. Differences between normal and retrovirus-transformed cells were also detectable in the shapes and positions of various bands.

It therefore seems worthwhile to continue with the development of FTIR microscopy for the diagnosis of malignancy and possibly even for the pinpointing the cause of the malignancy.

\section{References}

[1] M. Barbacid, Annu. Rev. Biochem. 56 (1987), 779-827.

[2] J.K. Bull, J.A. McCarter and S.M. Sunderland, Virology 56 (1973), 268-284.

[3] M. Diem, S. Boydston-White and L. Chiriboga, Appl. Spectroscop. 53 (1999), 148-161.

[4] H. Fabian, R. Wessel, M. Jackson, A. Schwartz, P. Lasch I. Fichtner, H. Mantsch and D. Naumann, SPIE 3257 (1998), $13-23$. 
[5] P. Franck, P. Nabet and B. Dousset, Cell. Mol. Biol. 44 (1998), 273-275.

[6] C. Gallo and F. Mcyskens, Prog. Exp. Tumor Res. 22 (1978), 216-219.

[7] S.B. Janet, Carcinogenesis 21 (2000), 405-426.

[8] H. Keith, B.A. Wells and J. Bernard, J. Am. Acad. Dermatol. 22 (1990), 1175-1195.

[9] C. Kristensen, N. Ashkenasy, R. Jain and A. Koretsky, Br. J. Cancer 79 (1999), 278-285.

[10] H.J. Kung, C. Boerkoel and T.H. Carter, Curr. Top. Microbiol. Immunol. 171 (1991), 1-25.

[11] M. Li, X. Huang and E. Gorelik, J. Virol. 73 (1999), 9178-86.

[12] H. Mantsch and D. Chapman, Infrared Spectroscopy of Biomolecules, John Wiley, NY, 1996, chap. 2, 6-9.

[13] S. Mordechai, S. Argov, A. Salman, B. Cohen, J. Ramesh, V. Erukhimovitch, J. Goldstein and I. Sinelnikov, SPIE 4129 (2000), 231-241.

[14] P. Pisani, D.M. Parkin, F. Bray and J. Ferlay, Int. J. Cancer 83 (1999), 18-29.

[15] B. Rigas and P. Wong, Cancer Res. 52 (1992), 84-88.

[16] B. Rigas, S. Morgello, I.S. Goldman and P.T.T. Wong, Proc. Natl. Acad. Sci. USA 87 (1990), 8140-8144.

[17] H. Susi, in: Structure and Stability of Biological Macromolecules, S.N. Timashett and C.D. Fasman, eds, Marcel Dekker, New York, 1969, pp. 641-659.

[18] P.K. Vogt, in: Comprehensive Virology, Vol. 9, H. Frankel-Conrat and R. Wagner, eds, New York, Plenum Press, 1977, pp. 341-455.

[19] P. Wong, S. Lacelle and H. Yazdi, Appl. Spectroscop. 47 (1993), 1830-1836.

[20] P. Wong, S. Goldstein, R. Grekin, A. Godwin, C. Pivik and B. Rigas, Cancer Res. 53 (1993), 762-765.

[21] P.T.T. Wong, R.K. Wong, T. Caputo, T.A. Godwin and B. Rigas, Proc. Natl. Acad. Sci. USA 88 (1991), $10988-10992$.

[22] P.T.T. Wong, T. Wong and F.K. M. Fung, Appl. Spectroscop. 47 (1993), 1058-1063.

[23] D. Yang, D. Castro, I. El-Sayed, M. El-Sayed, R. Saxton and Y. Nancy, SPIE 2389 (1995), 543-551. 


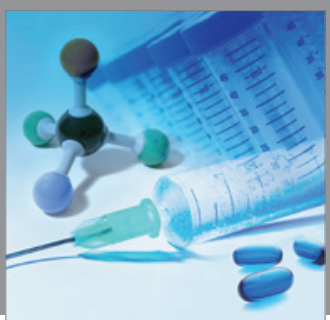

International Journal of

Medicinal Chemistry

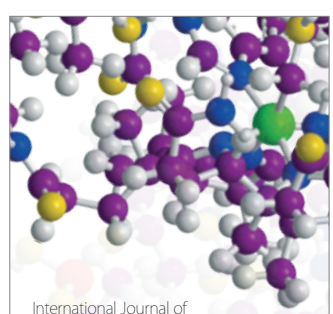

Carbohydrate Chemistry

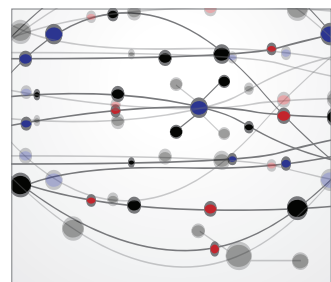

The Scientific World Journal
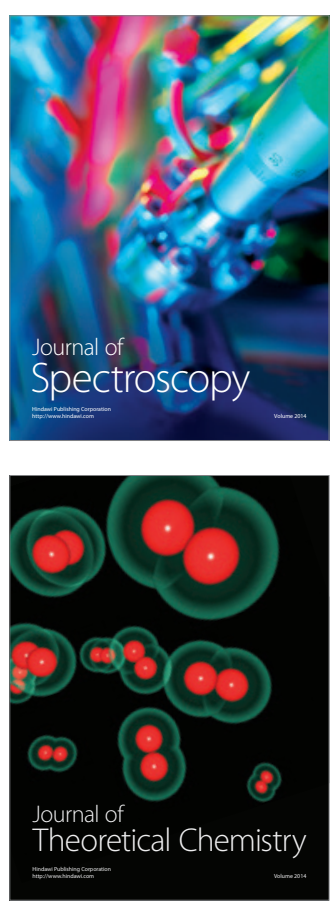
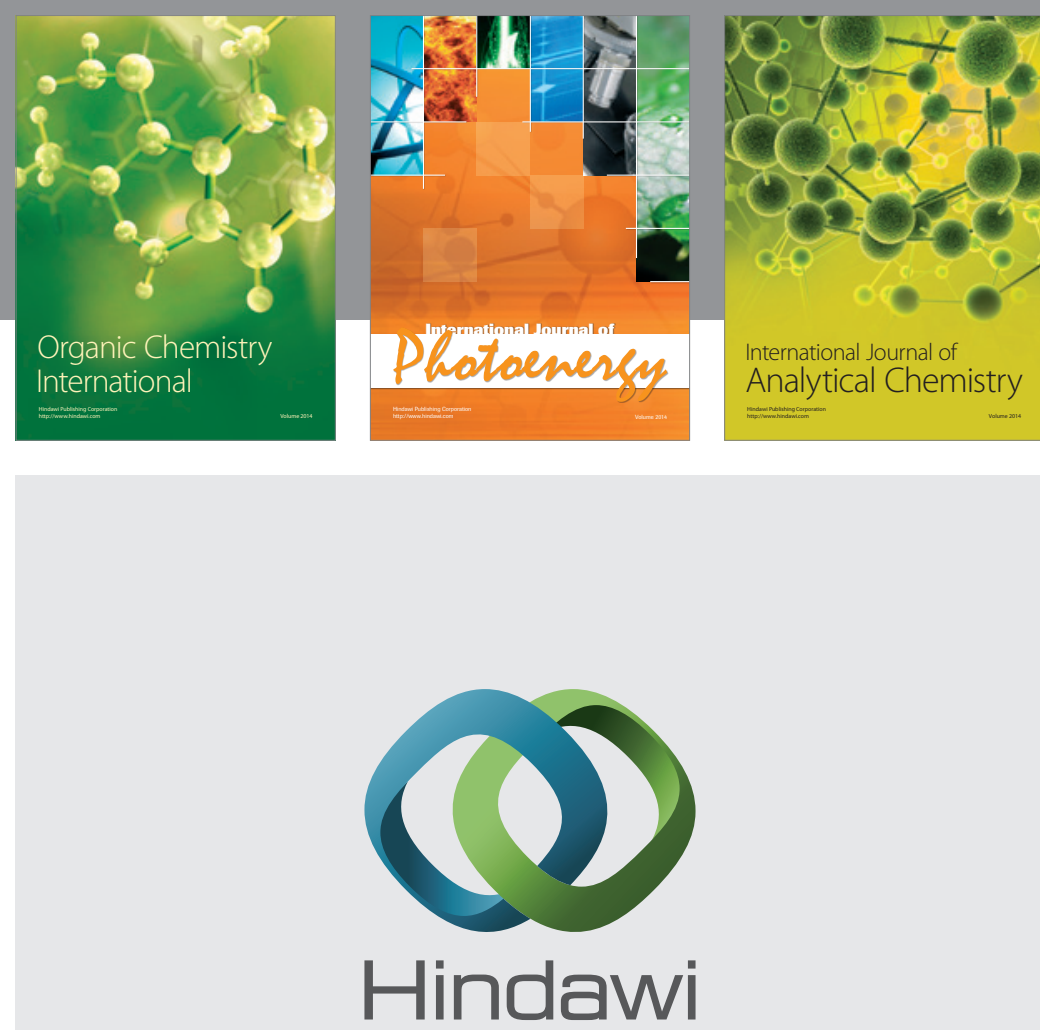

Submit your manuscripts at

http://www.hindawi.com
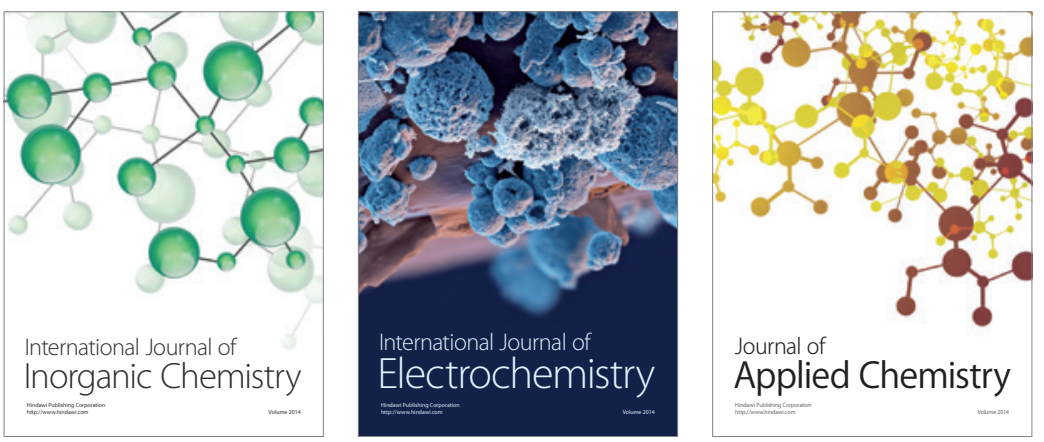

Journal of

Applied Chemistry
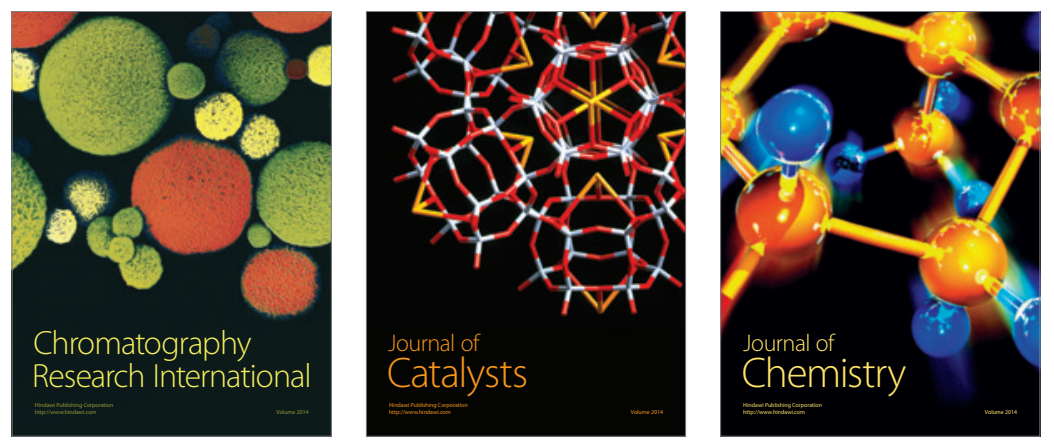
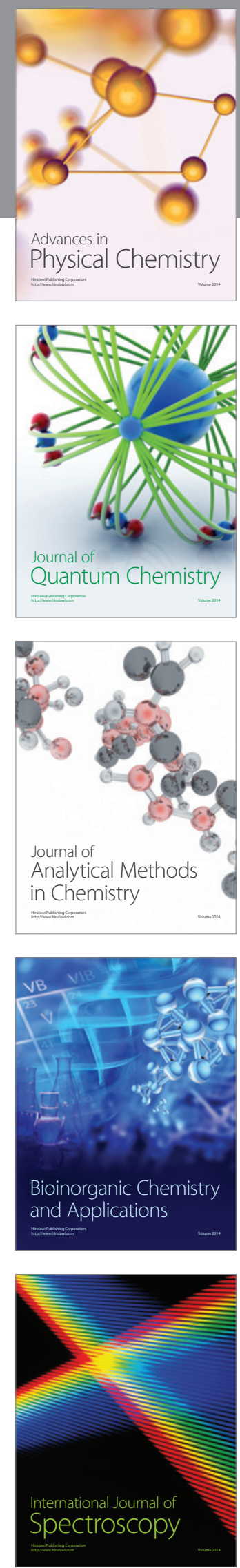